\title{
ANTROPOLOGIA E HISTÓRIA: REDIMENSIONAMENTO DE PARADIGMAS E UM CONVITE À CONGREGAÇÃO FESTIVA*
}

Mara Regina do Nascimento**

"Não estarão as estruturas mentais e intelectuais a enterrar-se, a mergulhar memórias, nos arquivos, em busca de uma ressurreição improvável?" Jean Baudrillard, em A ilusão do fim, p. 19.

“(...) que o acirramento dos componentes do moderno sistema técnico reencontre os elementos mais simples da ordem social anterior ao seu advento; que a grande destruição esteja presente, neurótica ou angustiada." Jean Duvignaud, em Festas e civilizações, p. 213.

Até agora estava posto: a História trabalha com grandes esquemas explicativos e, precisa, para isso, situar os acontecimentos em uma longa dimensão temporal que abarque (ou não) as variações dos problemas macroestruturais das sociedades; a Antropologia trabalha com fenômenos culturais, que só podem ser captados a partir de estudos que levem em conta um certo particularismo e uma declarada arritmia temporal.

* Este texto foi apresentado como trabalho de conclusão do primeiro semestre do curso de Especialização em Antropologia Social, do Departamento de Ciências Sociais da PUCRS, em 1996.

** Mestre em História do Brasil pela PUCRS, professora de História e pesquisadora bolsista da Fapergs.

Estudos Ibero-Americanos. PUCRS, v. XXIII, n. 1, p. 143-154, junho, 1997 
Porém, no momento em que somos levados a rever e a repensar conceitos tão solidamente colocados até então nas nossas análises intelectuais sobre as sociedades humanas, a possibilidade e a importância de questionar paradigmas cresce, não só na Antropologia, mas também na História, conduzindonos aos caminhos irreversíveis da transdisciplinaridade e da relativização.

Um redimensionamento teórico se faz necessário, uma vez que os antropólogos se vêem ainda embaraçados em uma discussão a respeito da validade da conciliação entre o funcionalismo - como método exemplar de trabalho de campo, mas que explica equivocadamente a realidade buscando o ponto de igualdade entre as sociedades humanas - e um modelo teórico que valorize a dimensão simbólica da vida social - onde reside a diferença. Tanto na Antropologia, como na História, o impasse que envolve o particular e o geral ou a unidade e a diferença é o cerne das disciplinas acadêmicas que lidam com a problemática teórica-metodológica dessas duas ciências.

Em relação à Antropologia, a controvérsia já completou quase cinqüenta anos, com o surgimento da perspectiva estruturalista e, algumas décadas antes, com a funcionalista que colocou à prova os pensamentos evolucionistas e etnocêntricos. Na ciência histórica, desde a inquietação trazida pelos Annales para a necessidade de uma História mais Social, até a arrojada Nova História Cultural, é que iniciou-se o debate acerca da pouca eficácia metodológica das interpretações de tendência abrangedora, que têm ainda hoje no marxismo sua maior expressão. A História Cultural, através do uso interpretativo que faz das fontes escritas, e suas propriedades literárias, procura conciliar o significado do texto - a unidade -, com a maneira como ele funciona, ou como ele é diversamente recebido - a diferença; da mesma forma como os antropólogos preocupam-se hoje em não apenas decifrar ou interpretar, mas sim dialogar com as culturas.

Décadas atrás os antropólogos e os historiadores baseavam seus estudos em concepções científicas que tinham como objetivo único verificar no que a sua própria cultura era estranha àquela estudada ou o quanto a sua sociedade estava fora das transformações observadas. Tudo, diz um historicista, muda, menos - obviamente - o esquema explicativo por ele usado para estudar essa mudança. O resultado desta postura é o estudo das diferenças sociais por meio de uma comparação em que aquele que compara está sempre fora do processo. ${ }^{1}$

DAMATTA, Roberto. Relativizando. Uma introdução à Antropologia Social. 4. ed. Rio de Janeiro: Rocco, 1993, p. 113. 
Sob essa perspectiva etnocêntrica historiadores e antropólogos focalizavam o objeto estudado pela ótica do estranhamento, da oposição, seja por considerar que tudo aconteceu num passado longínquo que evoluiu, seja por julgar que formas culturais situadas distantes geograficamente são a priori antagônicas.

Quando refletimos sobre hábitos higiênicos, por exemplo, esse sentimento de oposição logo se faz evidente. Mary Douglas, em seu estudo sobre os rituais ou hábitos de limpeza entre nós e entre os primitivos, mostrou-nos o quanto estamos habituados a tratar esse assunto de forma a considerar os nossos hábitos como coisa simples, facilmente explicável, ancorada na razão científica; enquanto que entre os primitivos esses mesmos hábitos estariam encobertos por uma auréola de mistério e de exotismo e, portanto, nada teriam a ver com os nossos. Ela diz: Nossas práticas são solidamente baseadas em higiene; as deles são simbólicas: nós matamos germes; eles afastam espiritos. Isto soa francamente como um contraste. Todavia, a semelhança entre alguns de nossos ritos simbólicos e nossa higiene é algumas vezes estranhamente estreita. $^{2}$

Utilizando-se de inúmeros exemplos de práticas higiênicas tomadas para o corpo e para a comida entre os povos primitivos (como o cuidado com o banho, as precauções com a carne crua ou as prevenções contra a saliva), a autora mostra o quanto muitas dessas práticas são semelhantes às nossas, mesmo que não desejemos ver isso: $\dot{A}$ medida que o tempo passa $e$ as experiências se empilham, fazemos um investimento cada vez maior em nosso sistema de rótulos. Assim uma tendência conservadora é incorporada. Isto nos dá confiança. (...) Fatos desconfortáveis, que se recusam a ser ajustados, nós os ignoramos ou os distorcemos a fim de que não perturbem aqueles pressupostos estabelecidos. ${ }^{3}$

A grosso modo, poder-se-ia assim traçar a derrocada, pela Antropologia, desta concepção de mundo: Bronislaw Malinowski ${ }^{4}$, primeiro a esfacelar a argamassa evolucionista, com sua concepção de que cada cultura é um todo operante e que por isso cada uma tem a sua forma de funcionar internamente, foi o primeiro a pensar na existência de um relativismo cultural. Depois dele,

2 DOUGLAS, Mary. Pureza e perigo. São Paulo: Perspectiva, 1976, p. 47.

3 DOUGLAS. Pureza e perigo. Op. cit., p. 52.

4 MALINOWSKI, Bronislaw. Uma teoria cientifica da cultura. 3.ed. Rio de Janeiro: Zahar, 1975. 
o estruturalista Claude Lévi-Strauss ${ }^{5}$, baseado em Marcel Mauss, nos presenteou com a idéia de que as sociedades estruturam-se pelas trocas, alianças e formas de comunicação que historicamente se estabelecem ao longo do tempo; essas trocas têm sempre um caráter simbólico e, dessa forma, a cultura é uma estrutura montada sob um conjunto de sistemas simbólicos, cuja dinâmica se dá pela relação entre o significado (conceito, idéia) e o significante (definição, suporte). Dessa forma, o signo não é uma totalidade autônoma, mas sim um sistema de regras que as sociedades convencionaram para si mesmas.

Clifford Geertz ${ }^{6}$, com a sua teoria interpretativa, dá um golpe final e decisivo no que ainda restava do evolucionismo e do funcionalismo: para ele, a vida social não tem forma, ela modifica constantemente as formas; tudo o que se escreveu até agora não passou de interpretação, não há uma realidade primeira - aquilo que o nativo, o entrevistado ou os manuscritos fornecem aos antropólogos são também interpretações e disso tudo não resulta mais do que teias de significações. Em Geertz, o homem é um animal suspenso nas teias de significado que ele próprio teceu.?

$\mathrm{Na}$ História, onde os esquemas totalizantes são uma marca distintiva, as tradicionais análises positivistas - que voltavam-se exclusivamente para a frio estudo das biografias e dos acontecimentos políticos - e das marxistas - que tendem a centralizar-se em conceitos rígidos como "modos de produção", "relações de trabalho" e "luta de classes" - tiveram como primeira oposição Fernand Braudel, fundador dos Annales e da concepção de que a História não se move apenas pelas contradições sociais, mas também porque existem, em qualquer processo histórico, ritmos e movimentos diferentes, rápidos e lentos; que não há um só movimento, mas sim acontecimentos históricos que ocorrem dentro de tempos breves e outros dentro de uma longa duração, assim como o movimento do oceano, que é feito tanto pela calmaria em alto-mar como pela agitação impetuosa da quebra das ondas.

Braudel foi a base teórica para os historiadores das mentalités, que, ao se preocuparem com a longa duração das representações coletivas, aproximaram-se definitivamente da Antropologia. Na História, foram os historia-

5 LÉVI-STRAUSS, Claude. As estruturas elementares de parentesco. São Paulo: Vozes e Universidade de São Paulo, 1976.

6 GEERTZ, Clifford. A interpretação das culturas. Rio de Janeiro: Zahar, 1978.

7 BIERSACK, Aletta. "Saber local, História local: Geertz e além". In: HUNT, Lynn. A nova história cultural. São Paulo: Martins Fontes, 1995, p. 108. 
dores da cultura que formam o que Lynn Hunt chamou de quarta geração dos Annales ${ }^{8}$, como Roger Chartier e Jacques Revel, que voltaram-se para a investigação dos fenômenos culturais como elementos objetivamente históricos e abriram espaço para a polêmica discussão a respeito das fronteiras disciplinares que se abrem hoje com a Nova História Cultural. A partir daí antropólogos como Clifford Geertz e Marshall Sahlins são utilizados por historiadores que se interessam também pela perspectiva antropológica da História, ou seja, pela chamada Antropologia histórica. Sob essa nova tendência paradigmática, unidade e diferença são colocadas como percepções complementárias, assim como também a interpretação e a desconstrução, o significado e o funcionamento. Segundo Lynn Hunt, nesses tempos de questionamento de paradigmas e de difícil demarcação de fronteiras entre as disciplinas, os historiadores não precisam escolher entre sociologia ou antropologia, ou entre antropologia e teoria literária para conduzirem suas pesquisas [...]. Os historiadores não precisam aliar-se obstinadamente a Clifford Geertz ou Pierre Bourdieu, nem a Northrop Frye ou Jacques Derrida $^{9}$. A escolha não precisa e nem tem como ser feita.

Sob o mesmo tipo de reflexão feita por Lynn Hunt, podemos ler, hoje, em Jean Baudrillard, que estamos perante um processo paradoxal de reversão, de um efeito reversivo da modernidade que, tendo atingido o seu limite especulativo e extrapolado todos os seus desenvolvimentos virtuais, se desintegra nos seus elementos simples, segundo um processo catastrófico de recorrência e de turbulência. ${ }^{10}$ A crise da modernidade representa a crise de seus paradigmas e isso atinge indistintamente os padrões teórico-analíticos dos campos das ciências, sejam das chamadas exatas ou das chamadas humanas. Diante disso, de que vale agora, por exemplo, a preocupação em analisar de que forma as sociedades produzem economicamente, tendo como parâmetro a racionalidade que ordena o modo de produção capitalista? $\mathrm{Ou}$ ainda, pensar-se, por exemplo, que historicamente, todas as sociedades terão um dia a sua revolução industrial, ou o seu socialismo, ou a tensão classista entre trabalhadores e patrões, ou que todas as nações subdesenvolvidas nada mais estão fazendo do que traçando um futuro previsível - o de tornarem-se

8 HUNT. A nova história cultural, Op. cit., p. 9.

9 HUNT. A nova história cultural. Op. cit., p. 21.

10 BAUDRILLARD, Jean. A ilusão do fim ou a greve dos acontecimentos. Lisboa: Terramar, s.d., p. 22. 
igualmente desenvolvidas conforme as nações da Europa Ocidental? Ou acreditar que os rituais mágicos e os atos de violência são opositores à nossa civilizada cultura ocidental?

À luz da razão moderna, que despreza as diferenças, muito se tentou esquadrinhar um modelo histórico de análise que tendia investigar basicamente os modos de produção ou dos avanços tecnológicos de uma sociedade, como seus verdadeiros termômetros. E o que se obteve com isso, me parece, foram quase sempre visões parciais, homogeneizantes ou tendenciosas.

Neste sentido, aquilo que julgava-se servir, sem questionamentos, para explicar a constituição do tecido social de qualquer agrupamento humano, caiu em desuso, fazendo surgir novas possibilidades de análise, que não somente a produção utilitária e o trabalho. A partir desse processo de reversão, ao qual refere-se Baudrillard, podemos examinar, interpretar e compreender uma determinada sociedade não pelo que ela produz, mas, ao contrário, pelo que ela não produz, a fim de procurar também aí uma forma, entre outras, de caracterizá-la. Hoje é cada vez mais recorrente o pensamento de que, como escreveu Jean Duvignaud, em 1973, o pressuposto de que a finalidade de todas as sociedades humanas é o trabalho e que a função principal das coletividades é a produção não passa de uma crença ao mesmo nivel da crença melanésia que aceita, por exemplo, que a morte não existe ..."

Fazendo uso das possibilidades analíticas proporcionadas pela Antropologia histórica (ou será que é de uma História antropológica?) vejo que a festa é um fenômeno histórico-cultural importante para a análise de uma determinada sociedade ou nação - a festa, como espírito de turbulência, e não apenas pelo sentimento de alegria que traz aos seus participantes. Quase sempre relegada a segundo plano pela maior parte dos historiadores ${ }^{12}$, a festa pela liberação das mentes e dos corpos, amolecimento das regras, efemeridade e fluidez de fins, representa um momento de transgressão, de inversão, um

11 DUVIGNAUD, Jean. Festa e civilizações. Rio de Janeiro: Tempo Brasileiro e Universidade Federal do Ceará, 1983, p. 128.

12 Peter Burke parece-me foi um dos poucos historiadores a se aventurarem por este terreno, ao escrever Cultura popular na Idade Moderna. São Paulo: Companhia das Letras, 1995; a grande maioria das análises sobre a festa ficou a cargo de literatos (como Mikhail Bakhtin) ou sociólogos e antropólogos (como Jean Duvignaud, Roger Caillois, George Bataille, Pierre Sanchis, Gilberto Freyre, Roberto DaMatta). Ainda assim, historiadores que analisaram a festa e sua dimensão histórica, colocaram-na diluída ou pulverizada dentro de algo maior que é a cultura popular e não como um elemento fundamental para a compreensão daquilo que chamamos de realidade vivida. 
pensamento desviante daquele voltado para as normas da vida cotidiana, que deveria ser cuidadosamente olhado pelos historiadores.

A festa é um estado, uma passagem, uma possibilidade de se voltar ao caos, conforme Roger Caillois. ${ }^{13}$ Para este autor, ela é antes de mais nada fator de aliança entre os homens. ${ }^{14}$ Num mundo marcado pelo interdito - aquilo que está na forma do sagrado, dos tabus e das leis -, ela é um período de profanação e de desordem. A festa é explosão, efervescência, concentração e febre. Na vida de severa compressão que levamos, sob a ordem "natural" do cosmos, onde há um lugar definido para tudo e um tempo determinado para os acontecimentos, a festa explode para revigorar em nós, através do excesso, aquilo que o tempo esgota. Ela quebra o ritmo do sagrado do cosmos para mantê-lo sempre vivo, para fazê-lo renascer sempre. Os deuses, com seus atos divinos, criaram as coisas: o tempo, a morte, o ritmo compassado da vida, o homem e a natureza; criaram a ordem no caos. A festa - o caos -, quando se finda, encontra novamente a ordem - o cosmos - , numa repetição dos gestos das divindades. É o mito do eterno retorno, ao qual se refere Mircea Eliade. Para ele, nas festas reencontra-se a dimensão sagrada da existência, ao se aprender novamente como os deuses ou os antepassados míticos criaram o homem $e$ lhe ensinaram os diversos comportamentos sociais e os trabalhos práticos. ${ }^{15}$ Participar da festa é aproximar-se do Tempo original.

O mundo profano é necessário para manter a ordem do sagrado; a festa é necessária para manter vivo o mundo profano. Assim, como a definiu George Bataille, a festa é a fusão da vida humana (...), uma conciliação amigável, $e$ cheia de angústia, entre as necessidades incompativeis. ${ }^{16}$ Ela é a mediação entre o mundo da imanência e o mundo dos espíritos.

Segundo Roger Caillois, entre vários povos da Austrália e entre os Tsimshians da América do Norte, no início, antes das leis impostas pelos antepassados, o mundo era o caos, nada estava definido e nem regulado, as metamorfoses e os milagres tinham ai seu lugar, os objetos deslocavam-se por si mesmos, as canoas voavam pelos ares, os homens formavam-se em animais e inversamente. Eles mudavam de pele em vez de envelhecer e de morrer. Todo

13 CAILLOIS, Roger. O homem e o sagrado. Lisboa: Ediçð̃es 70, 1988 (primeira edição em 1950).

14 CAILlOIS. O homem e o sagrado. Op. cit., p. 176.

15 ELIADE, Mircea. O sagrado e o profano. São Paulo: Martins Fontes, 1995 (edição francesa em 1957), p. 80.

16 BATAILLE. George. Teoria da religião. São Paulo: Ática, 1993 (edição francesa em 1973), p. 45. 
o universo era plástico, fluido e inesgotável. As colheitas cresciam espontaneamente e a carne voltava a desenvolver-se nos animais depois de eles terem sido esquartejados. ${ }^{17}$

Depois que as leis do cosmos foram criadas pelos deuses nada mais mudou: a morte foi introduzida, os desejos regulados, os interditos estabelecidos e ficou no homem apenas uma nostalgia de uma época em que tudo era permitido, mas que, em contraposição, era um mundo de trevas e de horror.

A comoção que a festa provoca é uma tentativa de reproduzir algo similar a este acontecimento da criação, quando reinavam a permissividade, o abuso, o excesso e o esquecimento, embora também existisse uma aflição intensa.

Por isso, concordo com Jean Duvignaud quando este afirma que: não existe uma história da festa, porque ela não se confina a uma cultura ${ }^{18}$ e que a nossa capacidade de violar, de transgredir o quadro geral da nossa vida é, provavelmente, a parte mais fecunda do nosso ser.(..). A festa corresponde a estes momentos de antecipação e que os principios estabelecidos da civilização (sobretudo urbana) tendem a reduzir as experiências, a transpôlas para os discursos escritos, para a religião, até mesmo para a ética. ${ }^{19}$ Não se trata de buscar novamente um modelo geral de explicação, mas sim de tentar compreender de que maneira a festa, sempre tão presente, se insere na formação histórico-social de diferentes sociedades.

Neste sentido, podemos ver a festa da mesma forma como vemos o sentimento religioso: está em toda a parte. Se, como aponta Durkheim, definir a religião é definir a própria realidade ${ }^{20}$, então definir a festa é compreender a configuração das teias sociais. As idéias de "mistério" atribuídas para os fenômenos religiosos e de "secundário" para a festa são uma invenção da modernidade. Para Durkheim, a religião nem sempre foi sinônimo de

17 CAILLOIS. O homem e o sagrado. Op. cit., p. 102. É bom lembrar que para nós, cristãos, no principio, Deus criou os céus e a terra. A terra, porém, estava informe e vazia; as trevas cobriam o abismo e o Espirito de Deus pairava sobre as águas ... Deus separou a luz das trevas ... Deus fez o firmamento e separou as águas que estão debaixo do firmamento daquelas que estão por cima... Bíblia Sagrada, Gênesis, cap. 1, versículos de 1 a 31.

18 DUVIGNAUD. Festa e civilizações. Op. cit., p. 211.

19 DUVIGNAUD. Festa e civilizações. Op. cit., p. 228.

20 DURKHEIM, Émile. As formas elementares de vida religiosa (o sistema totêmico na Austrália). São Paulo: Paulinas, 1989, p. 54. 
mistério; para separá-los é preciso ir mais atrás no tempo e verificar quando esse tipo de pensamento passou a predominar. Ele diz: Para os homens do século XVII, por exemplo, o dogma não apresentava nada de perturbador para a razão; a fé conciliava-se facilmente com a ciência e a filosofia ${ }^{21}$. A religião nas sociedades mais simples não é mistério, ela é uma maneira de compreender o mundo. Para ele [o primitivo] não há nada de estranho em se poder, pela voz ou pelo gesto, comandar os elementos, deter ou precipitar o curso dos astros, provocar ou fazer parar a chuva. Os ritos que emprega para assegurar a fertilidade do solo ou a fecundidade das espécies animais com que se alimenta não são, a seus olhos, menos racionais do que são, aos nossos, os procedimentos técnicos de que se servem as agrônomos com o mesmo objetivo. ${ }^{22}$

Em 1965, Mikhail Bakhtin, ao estudar o lugar do riso na sociedade medieval ocidental, fez uma afirmativa similar à durkheimiana; ele assinalou que as festividades (qualquer que seja o seu tipo) são uma forma primordial, marcante, da civilização humana. As festividades tiveram sempre um conteúdo essencial, um sentido profundo, exprimiram sempre uma concepção de mundo. ${ }^{23}$

É na modernidade - lugar privilegiado da idéia de que para tudo deve haver uma utilidade - que os dias permitidos para a festa terminaram por ocupar um lugar secundário na vida dos homens. No entanto, o espírito da festa ainda pode ser observado, como algo subjacente aos laços sociais, mesmo não estando tão evidente, como está nos rituais religiosos das chamadas sociedades simples ou no que ocorria, por exemplo, na Idade Média ocidental em que homens, fervorosamente crentes, dominados pela fé, irracionais aos nossos olhos, voltavam-se para a guerra como a um festejo, para um contato quase selvagem com o adversário a fim também de diversão, de paixão, de gasto de energia e de momento solene de consagração coletiva.

Então, por que será que, diante de tudo isso, a História deixou a cargo da Antropologia a análise da festa?

Sou tributária da opinião de que o Brasil oferece-nos um excelente terreno de análise sobre a festa, já que se constitui - desde o momento em que

21 DURKHEIM. As formas elementares ... Op. cit., p. 55.

22 DURKHEIM. As formas elementares... Op. cit., p. 56.

23 BAKHTIN, Mikhail. A cultura popular na Idade Média e no Renascimento. O contexto de François Rabelais. Brasilia: Edunb e Hucitec, 1993, p. 7 (grifos no original). 
passou a figurar nos quadros da modernidade, ou seja, desde a época dos descobrimentos marítimos - de uma nação caracterizada pela efervescência da mistura, onde o movimento, a hibridização de $\operatorname{códigos}^{24}$, o equilíbrio de antagonismos $^{25}$ e a transgressão das regras dão uma conotação festiva às formas da complexidade dos vínculos sociais.

Aqui, a hibridização é o que nos une e nos proporciona a concentração, o excesso e a transgressão típicas da festa, de que falam Roger Caillois e George Bataille.

No Brasil, não temos medo da mistura e nem do dispêndio de energia que isso representa; pelo contrário, estamos habituados a ela: a pluralidade está na etnia, na religião, na configuração das classes sociais, nos modelos de produção econômica, etc. No nosso pais, a ordem burguesa e moderna têm uma realização particular, pois nossa sociedade se mostra com uma estrutura social, num só tempo, rigidamente marcada pelos mecanismos, por assim dizer, universais e generalizantes das leis econômicas e amolecida, em particular, pela sua miscigenação, que é comandada pela conduta das trocas pessoais.

Roberto DaMatta, que estudou o carnaval e as procissões religiosas da Igreja Católica no Brasil como um fenômeno que está vinculado à nossa visão de mundo, discorreu sobre a transgressão como um elemento indissociável da nossa cultura. Para este autor, o carnaval está em múltiplos planos da nossa sociedade: a atmosfera carnavalesca, a partir de sua lógica subjacente pode ser reflexo e realidade do mundo social brasileiro. ${ }^{26}$ Esta peculiaridade brasileira tem para Roberto DaMatta uma explicação: Somos muito mais substantivamente dominados pelos papéis que estamos desempenhando do que por uma identidade geral que nos envia às leis gerais que temos que obedecer, caracteristica dominante da identidade do cidadão. ${ }^{27}$ Em outras palavras, pode-se dizer que no Brasil constantemente "estamos" alguma coisa mais do que "somos" alguma coisa ou alguém. Esse "estar", que carrega consigo a qualidade da efemeridade, é também a lógica da festa.

24 Tomo de empréstimo essa expressão da Profa. Dra. Léa Freitas Perez, que é minha orientadora na pesquisa que realizo a respeito da festa no Brasil.

25 Este termo é de Gilberto Freyre; autor que tem em Casa-Grande \& Senzala e Sobrados e Mucambos obras fundamentais para a compreensão da mestiçagem no Brasil.

26 DAMATTA, Roberto. Carnavais, malandros e heróis. Para uma sociologia do dilema brasileiro. 5.ed. Rio de Janeiro: Guanabara, 1990, p. 70.

27 DAMATTA. Carnavais, malandros e heróis. Op. cit., p. 161. 
Para Léa Perez, a heterogeneidade de nossa organização social se dá no plano de uma rede de relações múltiplas. Na nossa lógica social, o principio em vigor não é do tipo ou ... ou, ao contrário, trata-se, todo o tempo, de reunir, de re-ligar. É o principio de tipo e ...e e. ${ }^{28} \mathrm{~A}$ festa pode ser tomada, então, como um ângulo possível de análise histórica da sociedade brasileira e também, indo mais além, do processo de formação da cidade brasileira.

Aqui o fenômeno da festa é tão antigo quanto o surgimento das cidades. Ele esteve e está intimamente ligado à cidade, como uma forma de expressão social tipicamente urbana. O nascimento do nosso país no contexto moderno do mundo ocidental fez despontar uma novidade: a relação intima, direta e de amálgama entre o fenômeno urbano - juntamente com o progresso tecnológico e o processo de civilizar que lhe são inseparáveis - e as festas.

Desde o princípio aqui se misturaram diferentes códigos: o homem com rasgos marcantes de mentalidade medieval (cuja visão de mundo, mais ligada ao lúdico, ainda não colocava o Homem no centro de poder) veio exercitar e tornar possível um novo projeto que se pretendia redentor, humanista e iluminista; as etnias negra, indígena e branca, conquistadas e conquistadoras, realizaram relações de aversão e de entrecruzamento; os cultos de religião afro, os rituais indigenas e a beatice européia permearam os propósitos da secularização; os objetivos modernizantes ocorreram incidentemente com as práticas escravagistas; as normas do mercado coincidiram com a realização das trocas pessoais; razão e fé movimentaram, como uma procissão religiosa, a idéia de progresso; a capacidade de viver em movimento, em trânsito, típica da festa, mesclou-se à idéia do devir, moderna por excelência.

E em um universo onde o princípio básico de conduta é o da congregação de oposições, o do amolecimento das regras, da multiplicidade de objetivos, é preciso ver a festa como significado e significante e utilizar esse dado cultural fundamental em nossas análises históricas. É chegada a hora de nos perguntarmos se conhecemos o nosso país como julgamos e se não seria fundamental, para conhecê-lo e interpretá-lo, que nos dediquemos a uma ampla discussão teórico-metodológica, do mesmo porte da já encadeada entre franceses, americanos e ingleses em torno da transdisciplinaridade como um

28 PEREZ, Léa Freitas. Festa e civilização nos trópicos. Projeto de pesquisa apresentado à SCT (Secretaria da Ciência e Tecnologia) e ao CNPq (Conselho de Desenvolvimento Cientifico e Tecnológico), 1995, p. 3. 
instrumento incondicional do historiador que deseje ter na Antropologia histórica a possibilidade de um olhar menos abrangedor e mais dialógico e interpretativo em relação ao seu objeto de análise.

\section{BIBLIOGRAFIA}

BATAILLE, George. Teoria da religião. São Paulo: Ática, 1993.

BAUDRILLARD, Jean. A ilusão do fim ou a greve dos acontecimentos. Lisboa: Terramar, s.d.

BIERSACK, Aletta. "Saber local, História local: Geertz e além". In: HUNT, Lynn. A nova história cultural. São Paulo: Martins Fontes, 1995.

CAILLOIS, Roger. O homem e o sagrado. Lisboa: Ediçōes 70, 1988.

DAMATTA, Roberto. Carnavais, heróis e malandros. Para uma sociologia do dilema brasileiro. 5.ed. Rio de Janeiro: Guanabara, 1990.

- Relativizando. Uma introdução à Antropologia Social. 4. ed. Rio de Janeiro: Rocco, 1993.

DOUGLAS, Mary. Pureza e perigo. São Paulo: Perspectiva, 1976.

DURKHEIM, Émile. As formas elementares de vida religiosa (o sistema totêmico na Austrália). São Paulo: Paulinas, 1989.

DUVIGNAUD, Jean. Festa e civilizaçðes. Rio de Janeiro: Tempo Brasileiro e Universidade Federal do Ceará, 1983.

ELIADE, Mircea. O sagrado e o profano. São Paulo: Martins Fontes, 1995.

GEERTZ, Clifford. A interpretação das culturas. Rio de Janeiro: Zahar, 1978.

HUNT, Lynn. A nova história cultural. São Paulo: Martins Fontes, 1995.

LÉVI-STRAUSS, Claude. As estruturas elementares de parentesco. São Paulo: Vozes e Universidade de São Paulo, 1976.

MALINOWSKI, Bronislaw. Uma teoria cientifica da cultura. 3. ed. Rio de Janeiro: Zahar, 1975.

PEREZ, Léa Freitas. Festa e civilização nos trópicos. Projeto de pesquisa apresentado à SCT (Secretaria da Ciência e Tecnologia) e ao CNPq (Conselho de Desenvolvimento Cientifico e Tecnológico), 1995. 